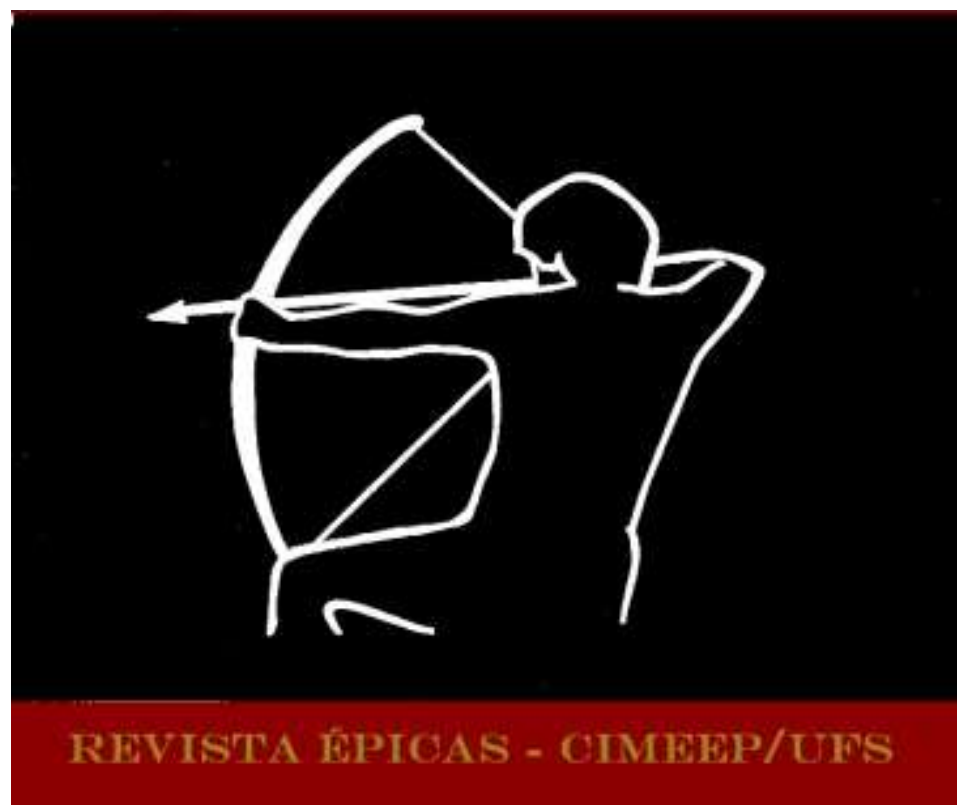

GHIDONI, Andrea. Canções de gesta ou epopeias? Tendências recentes e novos desenvolvimentos "antropo-literários" no estudo da epopeia românica. Trad. Antonio Trindade e Christina Ramalho. In: Revista Épicas. Ano 5, Número Especial 4, Março 2021, p. 77-97. ISSN 2527-080X. DOI: http://dx.doi.org/10.47044/2527-080X.2021vNE4.7797

\title{
CANÇÕES DE GESTA OU EPOPEIAS? TENDÊNCIAS RECENTES E NOVOS DESENVOLVIMENTOS “ANTROPO-LITERÁRIOS” NO ESTUDO DA EPOPEIA ROMÂNICA ${ }^{1}$

\author{
CHANSONS DE GESTE OR EPICP POEM? RECENT TRENDS AND NEW "ANTHROPO-LITTERARY" \\ DEVELOPMENTS IN THE STUDY OF THE ROMAN EPIC
}

Andrea Ghidoni ${ }^{2}$

Università degli studi di Macerata

RESUMO: O artigo apresenta uma revisão dos artigos mais recentes (publicados por volta da última década) que oferecem novos estudos da epopeia românica com perspectivas teóricas e antropológicas. A reflexão foi realizada em três direções: 1. o estatuto épico das canções de gesta; 2. o conceito geral de um épico construído com base em textos romanos; 3 . o desenvolvimento de conceitos antropológicos nos estudos literários românicos.

Palavras-chave: Canção de gesta. Epopeia. Epopeia românica.

\footnotetext{
${ }^{1}$ A versão original deste artigo, em francês foi publicado na revista Le Recueil Ouvert 2019. Referência completa: GHIDONI, Andrea. Chansons de geste ou épopée ? Tendances récentes et nouveaux développements "anthropo-littéraires" dans l'étude de l'épopée romane, Le Recueil Ouvert [En ligne], mis à jour le : 15/11/2019, URL : http://ouvroir-litt-arts.univ-grenoble-alpes.fr/revues/projetepopee/335-chansons-de-geste-ou-epopee-tendances-recentes-et-nouveaux-developpements-anthropo-litteraires-dans-I-etude-de-Iepopee-romane

${ }^{2}$ Andrea Ghidoni (Codogno, Itália, 1985) formou-se na Universidade de Pavia e obteve o título acadêmico de Doutor na Universidade de Macerata, onde colabora com a Cátedra de Filologia Românica após fazer um Pós-doutorado na Universidade de Namur. Suas principais publicações, que dizem respeito à epopeia romana, são as seguintes: a edição crítica da canção de gestA Gormont et Isembart (2013), Per una poetica delle chansons de geste. Elementi e modelli (2014), L'eroe imberbe. Le enfances nelle chansons de geste : poetica e semiologia di un genere epico medievale (2018)
} 
ABSTRACT: The article presents a review of the most recent articles (published around the last decade) proposing a theoretical or anthropological examination of the Romanic epic. The reflection was conducted in three directions: 1 . the status of "epic" of chansons de geste; 2 . the concept of epic genre built with the help of Romance texts; 3. the development of anthropological concepts in Romanic literary studies.

Keywords: Chansons de geste. Epic poem. Romanesque epic.

\section{Introdução}

Canção de gesta ou epopeia? Perguntava D. Poirion ${ }^{3}$ em 1972 em um artigo que pretendia ser a pedra angular da reflexão teórica sobre o gênero ao qual a poesia heroica romana poderia pertencer - e em particular a rica produção de textos em francês antigo. O texto questionava o automatismo que sempre levara os medievalistas a identificarem as canções de gesta com o gênero épico em sentido amplo, aproximando-as das epopeias antiga e clássica. Poirion, ao contrário, enfatizou a singularidade desse gênero da literatura medieval e preferiu usar o termo "heroico" para designá-lo. Em suma, a questão era a seguinte: é legítimo aplicar rótulos éticos - como diriam hoje em dia os antropólogos ${ }^{4}$ - aos textos da "literatura" medieval? ${ }^{5}$. Essa é a primeira questão que uma abordagem antropológica e teórica das canções de gesta e de outros textos heroicos romanos deve levar em conta. Duas outras questões, dois outros problemas conceituais, entretanto, podem ser vislumbrados por trás dessa questão.

A relação teórica entre o texto "épico" medieval e o conceito de epopeia não deve, de fato, ser entendida apenas em um sentido unilateral, de um ponto de vista puramente medievalista que se limitaria a perguntar como a inclusão das canções de gesta e dos cantares castelhanos no gênero mais amplo da epopeia internacional pode ser produtiva para essas famílias textuais medievais. A relação pode realmente ser bidirecional: é legítimo perguntar-se até que ponto a extensão do conceito épico aos textos romanos pode contribuir para o desenvolvimento da própria ideia que temos da epopeia. Assim, como interagem a Chanson de Roland ou o Cantar de Mio Cid com textos como a Ilíada, a Odisseia, a Eneida, o Gilgamesh, o Mahabharata, o Beowulf, e como é construído o conceito de épico? Essas questões constituirão o segundo eixo de nosso trabalho.

Uma terceira modalidade de comparação entre textos épicos é, no entanto, possível: se considerarmos os textos literários comparados como inequivocamente épicos, podemos então reuni-los para compará-los e

\footnotetext{
3 POIRION, Daniel. Chanson de geste ou épopée ? Remarques sur la définition d'un genre. In : Travaux de linguistique et de littérature, n. 10 (1972), p. 7-20.

${ }^{4}$ Conceitualizações éticas são aquelas que um observador externo aplica a uma cultura diferente da sua (por exemplo, as classificações teóricas estabelecidas pelo antropólogo sobre a população que examina, transferindo-as de sua bagagem conceitual), enquanto êmicos são os rótulos usados por membros de uma cultura para descrever fenômenos em sua própria cultura.

${ }^{5} \mathrm{O}$ uso de aspas para a palavra literatura no que diz respeito à cultura medieval (preferindo, em vez dela, o termo poético) deriva, como sabemos, de ZUMTHOR, Paul. Essai de poétique médiévale. Paris: Le Seuil, 2000 [1972].
} 
pensá-los como documentos antropológicos que nos permitem estudar como certos aspectos individuais são comuns a diferentes tradições culturais, por exemplo, graças à maneira como cada texto trata do mesmo tema.

Os três eixos que acabamos de delinear constituirão a estrutura deste artigo. Este será, portanto, baseado em livros e artigos publicados na última década, em estudos românicos, que questionam os textos heroicos da Idade Média românica ${ }^{6}$ através de reflexões teóricas ou comparativas. O presente trabalho não pretende ser exaustivo, mas ilustrativo, apenas orientando a reflexão sobre o gênero épico no que se refere aos estudos românicos. Delinearemos, através dos exemplos propostos, uma tripla modalidade em que a reflexão teórico-comparativa genérica sobre a epopeia românica pode se articular da seguinte forma: 1. o status épico da literatura heroica românica, uma condição necessária para qualquer reflexão antropológica e comparativa incluindo canções de gesta ou cantares; 2 . a construção de um conceito de gênero épico que leve igualmente em conta também os textos épicos românicos - ou seja, a redefinição do gênero por meio do confronto de concepções de mundo, de sociedade ou de homem expostas em textos épicos de várias origens -; 3. os aspectos individuais - temas, motivos, formas - que podem permitir a comparação entre os textos "épicos" românicos e outras tradições épicas de diferentes culturas. Neste último caso, as tendências recentes revelam um interesse por ferramentas comparativas, como emoções, o animal ou desejo mimético etc ${ }^{7}$.

\section{O status épico das canções de gesta}

\section{Gêneros medievais e gêneros medievalistas}

O artigo mais recente sobre a relação entre os gêneros heroicos medievais e o gênero épico foi publicado na Romênia em 2018 por Patrick Moran ${ }^{8}$. O artigo se propõe como uma continuação, depois de quase cinquenta anos, do artigo seminal de Poirion mencionado na introdução.

Moran toma como ponto de partida o problema da utilização do conceito de gênero nos estudos medievais, uma categorização fixada pela herança classicista de que os filólogos desconfiam, por colocar, assim, a noção de gênero sob a definição que descende da Poética aristotélica. Porém, no mesmo ano em que o artigo de Poirion apareceu, a recomendação de Paul Zumthor ${ }^{9}$ sobre a necessidade de se ter cautela antes do uso de rótulos de gênero acabou confundindo todos os pensamentos sobre os tipos de literatura medieval, sobre a aplicabilidade do próprio conceito de gênero no campo medieval, bem como sobre a busca de definições

\footnotetext{
${ }^{6}$ Essencialmente canções de gesta e cantares - e nesses conjuntos o exercício teórico e comparativo quase sempre se concentra nos dois protótipos, o Roland e o Cid.

7 No decorrer deste artigo, me permitirei fazer referência ao meu trabalho, que gira quase inteiramente em torno dessa questão da elaboração teórica da epopeia em geral e da definição do gênero das canções de gesta.

${ }^{8}$ MORAN, Patrick. Genres médiévaux et genres médiévistes : l'exemple des termes chanson de geste et épopée. In : Romania, vol. 136 (2018), p. 38-60.

${ }_{9}^{9}$ ZUMTHOR, Paul. Essai de poétique médiévale. Paris: Le Seuil, 2000 [1972]. p. 197.
} 
rigorosas para noções genéricas que, apesar de tudo, foram e ainda são utilizadas: "Essas referências pareciam indicar um direcionamento inovador para as reflexões na teoria genérica, é claro que se limitaram, em grande parte, à década de 1980, e que, até o momento, a questão parece ter estagnado no mesmo ponto. Os estudos medievais atuais, por conseguinte, adotam um compromisso pragmático diante de questões genéricas" ${ }^{10}$. Esse compromisso consiste em relembrar o fato de que a noção de gênero não se adapta à literatura medieval, ao mesmo tempo em que aceita passivamente os rótulos convencionais herdados de estudos anteriores. Moran insiste, entretanto, no fato de que as obras medievais podem ser classificadas em grupos, famílias ou classes, desde que se refiram à tradição de sua época e o número de obras difíceis de classificar seja bastante limitado. Segundo o autor, o conceito de gênero é, por isso, válido e seu uso não é anacrônico - caso se abstenha de usálo de forma prescritiva e clássica. O problema, em qualquer caso, não está no fato de que as obras da Idade Média seriam fluidas e inclassificáveis, senão no fato de que os gêneros medieval e medievalista não coincidem: o quadro fragmentário deixado pela tradição do manuscrito impede uma reconstrução clara do quadro dos gêneros medievais e, mesmo quando nos beneficiamos dos termos então usados pelos contemporâneos, achamos difícil reconhecê-los com base nos critérios - prosódico, ideológico, pragmático, de conteúdo social ou temático - pelos quais esses tipos foram definidos.

O domínio por excelência em que falta uma definição estrita de gênero, embora rótulos heterogêneos sejam usados casualmente, é o das canções de gesta, a que nos referimos sem muita precisão com os termos canção de gesta e epopeia. "O indicador mais claro dessa sinonímia quase perfeita se encontra no emprego sistemático que os medievalistas fazem do adjetivo épico quando se referem a elementos da canção de gesta [...]. A expressão canção de gesta não produziu nenhum adjetivo próprio: [...] o uso permanente do adjetivo derivado do substantivo epopeia ainda merece ser questionado"11.

"Canção do gesta" designa, desse modo, um grupo textual bastante rígido, definido a partir de critérios de forma e conteúdo e cujos limites às vezes podem ser permeáveis:salvo exceções individuais, é fácil distinguir tipologicamente um texto cujas estrofes assonantadas ou rimadas e os versos decassilábicos ou alexandrinos narram histórias relacionadas ao cronotopo carolíngio, de outro cujos octossílabos de rimas consoantes contam aventuras ocorrendo na corte arturiana. Esta é, pois, uma definição formal.

O conceito de epopeia, por sua vez, remete a uma tipologia transcultural, que se forja sobretudo no modelo homérico e que corresponde mais ou menos à seguinte definição: no nível "a epopeia o canto guerreiro de uma sociedade que nasce". Os dois níveis de leitura, legítimos e fecundos, devem, todavia, permanecer

10 MORAN, Patrick. Genres médiévaux et genres médiévistes. op. cit., p. 40. Os estudos mencionados por Moran são: FOWLER, Alastair. Kind of Literature. An Introduction to the Theory of Genres and Modes. Oxford: Oxford University Press, 1982; SCHNURWELLPOTT, Margrit. Aporien der Gattungstheorie aus semiotischer Sicht. Tübingen : Narr, 1983 ; SCHAEFFER, Jean-Marie. Qu'est-ce qu'un genre littéraire ? Paris : Seuil, 1989.

11 MORAN, Patrick. Genres médiévaux et genres médiévistes, op. cit., p. 44. 
distintos, sob pena de ambiguidade de definições. A heterogeneidade dos fundamentos desses dois conceitos vem à luz no discurso de Moran por meio do recurso aos vários mecanismos de produção de gêneros literários formulados por J.-M. Schaeffer ${ }^{12}$. O primeiro mecanismo é baseado nas propriedades enunciativas dos textos fala, narração etc. - enquanto o segundo define o gênero a partir de um conjunto de regras. $O$ terceiro mecanismo é genealógico: textos diferentes podem ser atribuídos à mesma tipologia porque compartilham uma tradição comum, uma convenção que também pode evoluir com o tempo. Finalmente, o quarto modo é analógico: os textos são agrupados a posteriori com base em características comuns. O uso do sintagma canção de gesta traça, desse modo, um isomorfismo genealógico, lembrando a tradição da arte poética medieval. Por outro lado, falar de uma epopeia invoca o quarto mecanismo, o da analogia, que agrupa os textos a partir de uma perspectiva comparativa e distanciada: "O princípio analógico pressupõe necessariamente um ato interpretativo: no caso da epopeia, esse ato interpretativo é de natureza antropológica"13.

Para Moran, outra forma de distinguir o limite que separa a canção de gesta daquele da epopeiareside na maneira como os elementos dessas classes são hierarquizados. Apoiando-se no conceito de protótipo, ou seja, na definição de uma classe a partir de alguns exemplares, o autor especifica que a definição do protótipo ${ }^{14}$ das canções de gesta foi condicionada pelo protótipo épico, a saber, a llíada, em benefício da elevação da Chanson de Roland ao status de modelo exemplar para estabelecer o que é a canção de gesta e o que não é: a escolha recaiu sobre esse texto porque ele partilha com a epopeia homérica um conteúdo bélico afirmado e constitui um dos primeiros textos de sua própria tradição cultural, acrescentando dessa forma, a uma caracterização pelo conteúdo, um critério temporal, uma vez que "A epopeia é uma espécie de fundação, um gênero auroral"15.

Moran propõe outro exemplo da heterogeneidade dos critérios cognitivos: os dois tipos são construídos com base em dois gradientes diferentes ${ }^{16}$. Enquanto os textos épicos são agrupados com base na gradiência de adesão - os membros desse grupo pertencem à classe de forma mais ou menos completa - as canções de gesta são diferenciadas por sua gradiência de centralidade - se distinguem entre periféricas e centrais; todas, porém, pertencem totalmente à classe -: desse modo, se as fronteiras da epopeia são fluidas, as das canções de gesta são mais claras. Ao adicionar uma apostila aos tipos de classificação descritos por Moran, acredito que seja apropriado usar o conceito de classificação politética de R. Needham. As classificações politéticas no campo antropológico foram parcialmente emprestadas de reflexões semelhantes nas ciências naturais: é uma

\footnotetext{
12 SCHAEFFER, Jean-Marie. Qu'est-ce qu'un genre littéraire? Paris : Seuil, 1989, p. 180-185.

13 MORAN, Patrick. Genres médiévaux et genres médiévistes, op. cit., p. 50. Sobre essa discussão, ver (entre outros) aqui o artigo de VINCLAIR, Pierre. Le roman fait l'épopée. In : Le Recueil Ouvert [En ligne], mis à jour le : 26/03/2018, URL : http://ouvroir-litt-arts.univgrenoble-alpes.fr/revues/projet-epopee/166-le-roman-fait-I-epopee.

${ }^{14}$ ROSCH, Eleanor. Natural Categories. In: Cognitive Psychology, n. 4 (1973), p. 328-350.

${ }^{15}$ MORAN, Patrick. Genres médiévaux et genres médiévistes, op. cit., p. 51-52.

16 LAKOFF, George. Women, Fires and Dangerous Things: What Categories Reveal about the Mind. Chicago: University Press, 1987.
} 
ferramenta de comparação que apresenta a vantagem de preferir, à clareza de uma taxonomia homogênea e monotética, uma espécie de classificação difusa em que o objeto de estudo é dissolvido em um feixe de traços sem qualquer hierarquia entre eles ou restrição de necessidade para determinar sua inclusão ou não dentro da classe - presentes em muitos objetos comparados, mas não necessariamente em tudo. Parece-me, portanto, que o conceito de epopeia, que afinal é uma espécie de molde antropológico e transcultural, evolui em um horizonte politético em que os critérios de seleção das canções de gesta são muito mais rígidos e cujas semelhanças textuais, sem ser completas, são muito mais claras ${ }^{17}$.

Moran conclui daí que é necessário, desse modo, redefinir o limite das canções de gesta, eliminando a ambiguidade do protótipo estabelecido com critérios heterogêneos, em razão dos quais o Roland é supervalorizado. Seria mais apropriado seguir uma lógica diferente e adotar como protótipos os textos compostos entre 1150 e 1250, o grupo majoritário da tradição. Isso nos permitiria considerar aspectos, marginais ou ausentes de Rolan, que caracterizam a produção do período seguinte.

As características de Roland, mais do que representativas de uma forma perfeita do gênero que só poderia se deteriorar ao longo das décadas e séculos subsequentes, apareceriam antes como marcas de uma época inicial, onde o gênero não desenvolveu ainda todo o seu potencial e tendências ${ }^{18}$.

\section{Poética das tradições das gestas}

Meu próprio trabalho me levou a conclusões paralelas, e gostaria de apontar aqui alguns prolongamentos possíveis ${ }^{19}$.

Individualistas e tradicionalistas propuseram modelos genealógicos para canções de gesta de tradições ou textos únicos: o manuscrito do Roland. Foi produzido por um poeta que estudou crônicas monásticas ou é o resultado mais recente de uma longa tradição principalmente oral e derivada de fatos históricos? A mesma pergunta foi feita para o Guillaume, para o Gormund e Isembart e para todos os outros poemas. Contudo, a imagem foi fragmentada e não temos uma visão geral: se nossas primeiras canções (Roland, Gormund, Guillaume) apresentam afinidades notáveis - bem como diferenças inegáveis: o Gormund está nos octossílabos

\footnotetext{
17 NEEDHAM, Rodney. Polythetic Classification: Convergence and Consequences. In: Man, n. 10 (1975), p. 349-369.

18 Original em francês: Les caractéristiques du Roland, plutôt que représentantes d'une forme parfaite du genre qui n'a pu que se dégrader pendant les décennies et les siècles subséquents, apparaîtraient plutôt comme les marques d'une ère précoce, où le genre n'a pas encore développé toutes ses potentialités et tendances. MORAN, Patrick, Genres médiévaux et genres médiévistes. op. cit., $p$. 58.

${ }_{19} \mathrm{GHIDONI}$, Andrea. Per una poetica storica delle chansons de geste. Elementi e modelli. Venezia : Edizioni Ca' Foscari, 2015 (en ligne : http://edizionicafoscari.unive.it/it/edizioni/libri/978-88-97735-91-5/); The Origins of the Narrative Structures in the Chansons de Geste. In : Perspectives médiévales, n. 35 (2014), URL : http://peme.revues.org/4321; Sviluppo diacronico e diatopico delle chansons de geste . In : DIVIZIA, Paolo (éd.). Il viaggio del testo. Atti del Convegno internazionale di Filologia italiana e romanza (Brno, 19-21 giugno 2014). Alessandria: Edizioni dell'Orso, 2017, p. 395- 406 ; Modello ossidionale e modello agiografico : patterns a confronto nella preistoria delle chansons de geste. In : CARERI, Maria (éd.) Par deviers Rome m'en revenrai errant" XXe Congrès International de la Societé Rencesvals pour l'étude des épopées romanes. Roma : Viella, 2017, p. 515-525.
} 
- tanto pela forma como pelo conteúdo - o modelo "martirológico" comum a todos, com um herói que morre segundo um tema comum -, quando e como nasceu o gênero das canções de gesta - não os poemas individuais, mas a sua tradição formal?

Minha hipótese de trabalho é que as três testemunhas arcaicas representam uma fase da tradição das gestas no final do século XI ou no início do século seguinte, em que uma ou mais oficinas, compostas por "profissionais" da arte verbal, dotados de uma certa cultura, que souberam escrever em um vernáculo formalizado, para dizer o mínimo, foram desenvolvendo gradualmente, não sem contatos e influências recíprocas, um modelo formal, linguístico e de conteúdo, que teria modificado profundamente a nebulosa polimorfa e instável das tradições heroicas anteriores (principalmente oral e folclórica) ${ }^{20}$. A introdução da escrita, ou pelo menos de novos modelos de escrita que se impõem e difundem, teria dado origem ao gênero da canção de gesta como a conhecemos hoje: um número limitado de textos lançando um modelo de prestígio que logo se tornou essencial, pelo menos no nível formal. O modelo "martirológico" logo deixa de exercer sua influência no nível do conteúdo, enquanto a tradição formal persiste de maneira mais ou menos estável. Como resultado, aparecem textos que se assemelham aos primeiros espécimes em prosódia e linguagem, embora se desviem deles no assunto, nos padrões narrativos e no modelo heroico. Para representar graficamente essa passagem, propus pessoalmente como comparação a figura da ampulheta ${ }^{21}$ que tem duas extensões divergentes separadas por uma passagem estreita: uma série de tradições dispersas e diversificadas é reorganizada sob a influência do prestigioso modelo de textos arcaicos, notadamente Roland, incorporado em um número limitado de textos realmente limitado, e não apenas devido à natureza aleatória da herança manuscrita -; este modelo de conteúdo então desaparece, permitindo assim que uma pluralidade de modelos heroicos reapareça, ainda que, em novos textos escritos, a marca desse primeiro modelo seja reconhecida. A onda literária que segue os textos fundadores, no século XII e início do século XIII, desenha seus próprios padrões narrativos da tradição popular anterior. A precedência é então de tipo formal e não apenas cronológica: designa as tradições ainda não reformuladas de acordo com o cânone das novas gestas. Tomemos por exemplo um modelo "obsidional" em que os Aymerides lutam não em uma batalha campal, mas durante um cerco: a natureza arcaica desse modelo narrativo é atestada no Fragment de la Haye [Fragmento de Haia] (séculos X-XI); os motivos que Ihe são fixados reaparecem em fragmentos ou directamente em Narbonnais, na assonância do Narbonnais [Cerco de Narbonne], no Siège de Narbonne assonancé [Cerco de Barbastre], na Prise d'Orange [Tomada de Orange].

\footnotetext{
${ }^{20}$ Ver GHIDONI, Andrea. Per una poetica storica delle chansons de geste, op. cit, p. 51-64. O modelo elaborado a partir por exemplo de HOEPFFNER, Ernest. Les rapports littéraires entre les premières chansons de geste. In : Studi Medievali, n. 4 (1931), pp. 233-258; n. 6, p. 45-81; AVALLE, d’Arco Silvio. Cultura e lingua francese delle origini nella Passion di Clermont-Ferrand. Milano-Napoli : Ricciardi, 1962 ; WATHELET-WILLEM, Jeanne (1964). À propos de la technique formulaire dans les plus anciennes chansons de geste. In : RENSON, Jean (éd.). Mélanges de linguistique romane et de philologie médiévales offerts à M. Maurice Delbouille. Gembloux : Duculot, 1964, vol. II, p. 705-27.

${ }^{21}$ GHIDONI, Andrea. Per una poetica storica delle chansons de geste, op. cit, p. 74.
} 
Temos aqui um modelo heroico de guerra bastante diferente do modelo rolandiano, específico para um grupo de personagens (os Aymerides) ${ }^{22}$.Graças aos diagramas narrativos, à sua reprodução em canções e em contextos muito específicos, bem como à sua possível confirmação em textos muito antigos, é possível traçar os agrupamentos de tradições heroicas - que se coagulavam em torno de identidades esquemáticas, uma espécie de microgêneros - anterioresao modelo do final do século XI.

Na tentativa de preencher a falta de terminologia para indicar o que é específico das canções de gesta, propus o neologismo gestique, eu gesticulo em italiano. Desse modo, a palavra epopeia, imprecisa e vaga para designar a especificidade da família histórica, é deixada de lado para falar desses textos. Em vez disso, para identificar os materiais narrativos que precedem o modelo e que ressurgiram no século XII, podemos falar de proto-gestique, termo em que o prefixo proto não tem um valor cronológico rígido.

O valor prototípico do Roland, que de forma alguma deve ser isolado de outros textos arcaicos, na medida em que a força modeladora deve ser dividida em uma estreita pluralidade de textos, é matizado no sentido histórico: o Roland é exemplar para um determinado período, a virada do final do século XI, após o qual o modelo heroico martirológico é substituído por outros modelos heroicos do século XII, esquematizados de acordo com as convenções narrativas populares. O modelo martirológico, considerado apropriado para um experimento ideológico e formal, poderia assim ter sido formulado nesses poucos textos iniciais ou, mais provavelmente, teria sido um dos modelos em vigor na lendária tradição carolíngia.

A meu ver, o caráter "épico" das canções de gesta não diz respeito tanto ao conteúdo, ao modelo heroico, à ideologia expressa, senão à função culturológica desses textos, que estabelecem novas tradições escritas a partir de um material oral sem forma e fracamente determinada pelas tradições literárias ${ }^{23}$. Esses textos oscilam entre canonização e experimentalismo; as operações culturais que oferecem muitas vezes não são cumpridas. Em suma, é em termos de dispositivos textuais dentro das culturas que um perfil "épico" pode ser identificado.

\section{Contribuições românicas para o conceito de epopeia}

Moran, assim, apresentou propostas sobre o caráter "épico" das canções de gesta e tentou definir o conceito de gênero medieval. Em vez disso, os seguintes trabalhos serão considerados exemplos de outro tipo de abordagem: uma definição da epopeia que também pode levar em conta os textos da Idade Média românica.

\footnotetext{
${ }^{22}$ A esse respeito, ver GHIDONI, Andrea, Modello ossidionale e modello agiografico, op. cit.

${ }^{23}$ GHIDONI, Andrea. Per una poetica storica delle chansons de geste, op. cit, p. 65-88. Acerca da funçãoda da apopeia como « dispisitivo cultural ", ver também : GHIDONI, Andrea. Narrazioni eroopoietiche mediolatine: "punteggiature" nell'evoluzione delle letterature profano-volgari”. In : Mittellateinisches Jahrbuch, vol. 53, n. 3 (2018), p. 399-422.
} 
Se, nos casos anteriores, se questionou a possibilidade de se examinar um gênero literário de uma cultura específica de uma perspectiva antropológica, aqui a intenção é, ao contrário, construir conceitos transculturais, com validade antropológica, por meio da comparação entre textos que compartilham uma semelhança familiar - mesmo que essa afinidade seja em parte recomendada e veiculada pela tradição científica.

De forma mais ou menos acentuada, os exemplos de críticas que vamos analisar se opõem a uma concepção aristotélica da epopeia, definida como sendo notadamente monolítica e monológica, puramente guerreira, e buscam, pelo contrário, promover uma interpretação dos textos classificados nesse gênero que enfatiza a polifonia, no sentido bakhtiniano do termo, bem como o funcionamento - o "trabalho", Wirkung (efeito) - desses "dispositivos" textuais dentro das culturas e sociedades que os moldam. O resultado dessas comparações pode não se aplicar a todos os produtos da família épica: em vez disso, tendemos a definir tipos específicos de epopeias ou textos épicos. Dentro desse gênero, às vezes muito indiferenciado, é possível fazer distinções com base na forma como os textos são compostos, em sua forma, em seu conteúdo - distinções que nos permitem pensar mais precisamente em textos importantes. Ampliando as condições socioculturais em que esses dispositivos textuais nascem, demonstramos também a rígida lógica estatal que torna as epopeias os mais antigos testemunhos de uma tradição cultural.

\section{(Epische Wirkung) Efeito épico e trabalho épico}

Joachim Küpper ${ }^{24}$ oferece uma análise da epopeia como um esforço para construir uma nova realidade, estudando a relação entre a narrativa e seu significado transcendente e metafísico em certos textos épicos da Europa Ocidental. Ele estuda a llíada, a Odisseia e a Eneida para o mundo antigo e concentra-se em três obras para o mundo medieval: o Roland, o Cantar de Mio Cid e o Nibelungenlied. O que está em jogo aqui é a relação entre o plano terreno e o plano transcendente; por conseguinte, entre o homem e a esfera divina: a relação entre as vicissitudes humanas da guerra e a divindade também determina o significado da história humana ou dos eventos relacionados. Conquanto o conceito de epische Wirkung (trabalho épico) seja central para ele, sua ação e resultado mudam nas várias culturas que deixaram textos épicos. Através deste trabalho, um modelo metafísico emerge.

J. Küpper opõe epopeias antigas e medievais. Desse modo, na epopeia homérica, os deuses não são de forma alguma transcendentes, porque são entidades antropomórficas que, como os humanos, estão sujeitas aos valores e fraquezas do homem. Não há, dessa maneira, nenhum significado transcendente nos eventos, que permanecem soluções públicas para fatos privados; o heroico mundo homérico é "um mundo sem grande significado" 25 . O motivo da ação heroica reside puramente no senso de honra, dentro de uma estrutura social

${ }^{24}$ KÜPPER, Joachim. Transzendenter Horizont und epische Wirkung. Zu Ilias, Odyssee, Aeneis, Chanson de Roland, El Cantar de mío Cid und Nibelungenlied. In: Poetica, vol. 40 (2008), p. 211-267.

25 Ibid., p. 215 
tribal e patriarcal. É nessa concepção de transcendência que podemos ver "a elaboração das diferenças entre épicos antigos e ocidentais"26.

A passagem do politeísmo ao monoteísmo causa, de fato, uma mudança de perspectiva em épopeias como Roland e Mio Cid. Nesses textos - especialmente no poema francês, mais debilmente no cantar castelhano - prevalece um sentido quase escatológico, de modo que a função do herói é a defesa e propagação do ideal cristão, que se manifesta por ele, cujo dever será o de ser sacrificado, como missão e como história sagrada. Visto que não há outra realidade senão a história guiada pela Verdade, todos os eventos são uma repetição de fatos sagrados, de acordo com a leitura figurativa das escrituras. Enquanto na epopeia antiga a função da narrativa épica era exibir uma escala de valores puramente humana - o senso de honra - na Idade Média outras funções foram articuladas: “As epopeias são exortações funcionais ao combate. [...] Mais do que qualquer outro gênero que colocamos sob a rubrica de 'literatura', as epopeias são textos que propagam - e talvez produzam - ideologias. O que se poderia chamar de caráter militante ou mesmo a eficácia do Ocidente cristão no combate pode muito bem ter fundamentos tecnológicos. Entretanto, ainda assim, estes devem primeiro ser criados. Dessa forma, não se pode descartar a ideia de que muito do que nos distingue de nossas raízes antigas, bem como de outras raízes concorrentes, é o fato de o mundo monoteísta ser completamente significativo e futurista"27. Tal é a epische Wirkung, um rótulo que enfatiza o trabalho épico, o esforço para construir uma nova realidade, para fundá-la.

Uma Sonderstellung (posição especial) na epopeia medieval seria, no entanto, representada pelo Nibelungenlied, que, embora compartilhando com a epopeia antiga e medieval a mesma escala de valores bélicos, adquire um status singular à medida que "a história é contada ali em enigmas. $O$ texto não apresenta em primeiro plano nenhum jogo de coragem ou honra, não encena um mundo de sentido superior, é um único enigma narrativo desdobrado" 28 . Por exemplo, a maldição do tesouro Nibelungo paira sobre toda a história, mas nunca é explicitada: "Na forma de ruptura de todos os fundamentos da coerência semântica, o solo mítico primordial, que antecede a trama do Nibelungenlied, é imediatamente introduzido de forma fragmentada no fluxo narrativo da Aventura" ${ }^{29}$. Enquanto que a epopeia antiga reduz os eventos a um jogo de honra e afeição inteiramente humana, e a medieval liga a história à transcendência cristã, o mundo do poema germânico segue sua própria lógica, mas não articula isso.

\footnotetext{
${ }^{26}$ Ibid., p. 215-216.

27 Ibid., KÜPPER, Joachim. Transzendenter Horizont. op. cit. p. 240-241: “Epen sind funktional Exhortationen zum Kampf. [...] Mehr als jedes andere Genre, das wir unter dem Rubrum "Literatur" führen, sind Epen ideologie-propagierende, ja vielleicht - produzierende Texte. Die, man kann sagen Militanz oder, man kann auch sagen Effektivität des christlichen Okzidents im Kampf mag auf technologischen Grundlagen berühren. Aber diese müssen erst geschaffen werden. So ist es nicht ausgeschlossen schlechthin, daß vieles, was uns von unseren antiken Wurzeln und auch von anderen, konkurrierenden unterscheidet, darin gründet, daß die monotheistische Welt eine ganz und gar sinn- und zukunftserfüllte ist".

${ }^{28}$ Ibid., p. 246: "eine Geschichte in Rätseln gibt. Der Text präsentiert an erster Stelle kein Spiel von Mut und Ehre, er inszeniert keine Welt mit einem höheren Sinn, er ist ein einziges, narrativ entfaltetes Enigma".

${ }^{29}$ Ibid., p. 248.
} 
Küpper chega à conclusão de que "a epopeia como gênero é uma literarização não homogênea de um horizonte ainda 'escondido'”30. A forma e o conteúdo ideológico dos textos épicos, desse modo, mudam dependendo de como esse horizonte é "habitado", e a epopeia, através do poema dos Nibelungos, também pode aparecer de forma fragmentada.

Uma representação da epopeia como uma máquina, dispositivo, mecanismo que "funciona" também esteve no centro do livro de F. Goyet de 2006, Penser sans concepts [Pensar sem conceitos] ${ }^{31}$. A própria essência do gênero épico aqui é sua função, ou seja, uma forma de pensamento político ${ }^{32}$. A Chanson de Roland, por exemplo, apresenta de forma narrativa o problema do poder real dilacerado, no início do século XII, pelas forças centrífugas do feudalismo e, assim, prepara a chegada do renascimento da monarquia por volta do ano 1200. 0 texto épico, dessa forma, enfrenta a crise política ao introduzir na narrativa os valores antagônicos em jogo que serão interpretados pelos personagens. A operação é realizada de duas maneiras: se na superfície a estrutura política é simplificada, ao criar oposições claras e bipolares, ela se complexifica profundamente e torna as partes envolvidas ambíguas. Ganelon, assim, será inexoravelmente condenado pela pior traição, embora aja de acordo com as regras feudais; para conseguir sua condenação, é necessário recorrer ao julgamento de Deus via duelo judicial. O trabalho épico aqui consiste justamente em que, por "tratar o material político de forma polifônica [...] a epopeia é um texto absolutamente apartidário"33. Essa teoria possibilitou à pesquisadora, em artigo de $2016^{34}$, pensar a epopeia tanto no mundo moderno quanto no antigo. Certamente, F. Goyet especifica que se dirige aqui apenas a um tipo particular de texto épico, que ela propõe chamar de epopeia de refundação, e não à epopeia em geral ${ }^{35}$, todavia esse tipo de texto é tão moderno quanto antigo: o principal é esse "trabalho" que permite articular posições políticas e que a literatura realiza continuamente. A análise do subgênero "epopeia de refundação" gira em torno de dois pontos fundamentais: seu papel público e a polifonia do texto. A epopeia é política porque é produto de tempos difíceis. Os valores da sociedade não são simplesmente exibidos como a definição convencional da epopeia sugere; Goyet, como Küpper, vê isso como uma reflexão com consequências políticas muito maiores. Para ela, essa reflexão mobiliza todos os traços épicos: precisamos de toda a extensão

\footnotetext{
30 Ibid., p. 267.

${ }^{31}$ GOYET, Florence. Penser sans concepts. Iliade, Chanson de Roland, Hôgen et Heiji monogatari. Paris: Honoré Champion, 2006, p. 7: “A epopeia bélica é uma máquina pensante gigantesca. A guerra que ela descreve é uma metáfora, que imita uma crise pública contemporânea a fim de dar-lhes os meios para compreendê-la intelectualmente. Na ausência de ferramentas conceituais [...] (históricas, jurídicas, filosóficas), a epopeia permite uma compreensão obscura, mas profunda e efetiva" [Nossa tradução).

32 Ibid., p. 357.

33 Ibid., p. 567.

${ }^{34}$ GOYET, Florence, "L'épopée refondatrice : extension et déplacement du concept d'épopée", in Le Recueil Ouvert [Online], atualizado em: 31/05/2018, URL: http://ouvroir-litt-arts.univ-grenoble-alpes.fr/revues/projet-epopee/165-le-travail-epique-definition-de-l-epopeerefondatrice.

35 "Nem todos os textos carimbados como "epopeias" desempenharam esse papel de refundação, e, ao invés de tentar definir a epopeia em geral e sub specie æternitatis, pode ser interessante definir esse subgênero particular que torna possível inventar a novidade política". [Tradução nossa do artigo original]
} 
do texto, todos os conflitos que ele representa e as incontáveis narrativas paralelas a ele relacionadas, para ver gradualmente todas as implicações de modelos políticos concebíveis emergirem. O conceito de polifonia, considerado por Bakhtin como uma marca do romance moderno, é reivindicado também para a epopeia, sem, contudo, descartar simplesmente o monologismo: o último é desclassificado pela poética política da epopeia, porque a dialética dos modelos políticos é paradoxalmente realizada na simplificação e no esquematismo.

\section{O texto épico como um "dispositivo" cultural}

Enquanto Küpper vê a epopeia como uma representação metafísica da realidade, da sociedade e da história, e Goyet considera a presença de um modelo político inovador como condição para refundar textos épicos, meu próprio trabalho ${ }^{36}$ me levou a pensar que o caráter épico de um texto também pode ser determinado por sua função em uma cultura. Meu ponto de partida é a importação no âmbito - cronológico e geográfico - da Idade Média europeia de uma definição formulada por Richard Martin ${ }^{37}$ no campo da literatura homérica. A epopeia não é um gênero, mas um supergênero: um texto épico é um recipiente unmarked (não marcado) como outras formas tradicionais, é um texto expansivo que se impõe - ou tenta se impor - como uma síntese ou uma reformulação de uma cultura e suas formas narrativas. Não obstante, ao mesmo tempo, é um texto marcado, onipresente, porque ocupa um lugar central na cultura sobre a qual atua. Essa definição se concentra mais na função do dispositivo textual e em sua relação com a memória cultural na qual está inserido do que em uma qualidade substancial. Poderíamos, a rigor, reduzir o raio dessa definição, colocando uma restrição de conteúdo: a história deve apresentar um sujeito heroico - embora cada cultura tenha seu próprio conceito de herói. Muitos dos primeiros textos das culturas vulgares medievais, entre os quais podemos incluir o Beowulf, o Hildebrandslied, o Culhwch ac Olwen, a Chanson de Roland, o Nibelungenlied, o Digenis Akritas - com a adição de dois textos seculares em latim, Waltharius e Ruodlieb -, apresenta de forma mais ou menos pronunciada uma propensão para a "coleção" cultural: o Beowulf foi definido, por exemplo, como summa litterarum ${ }^{38}$ e, por isso, poderia ser considerado o texto épico por excelência. Outro texto investido dessa função de "sillogé"39 (arquivo, acervo) na tradição narrativa que busca inovar, sintetizar e reformular é Culhwch ac Olwen, um texto galês do final do século XI. É uma narartiva vagamente emoldurada por uma Brautwerbung (busca pela noiva), na qual está inserida uma coleção em série de aventuras vividas pelo Rei Arthur - o personagem central do romance arturiano, um paradoxo curto-circuito entre os dois gêneros. De forma que o caráter polifônico da epopeia e sua

\footnotetext{
${ }^{36}$ GHIDONI, Andrea. Cultura e poetica dei dittici epici medievali. In: PIOLETTI, Antonio; RAPISARDA, Stefano (éd.). Forme letterarie del Medioevo romanzo : testo, interpretazione e storia XI Congresso Società Italiana di Filologia Romanza (Catania, 22-26 settembre 2015). SOVERIA Mannelli: RUBBATTINO, 2016, p. 237-253; Forme epiche arturiane : polifonia medievale e preistoria del romanzo nel Culhwch ac Olwen. In: BARBIERI, Alvaro; GREGORI, Elisa (éd.). Commixtio. Forme e generi misti in letteratura. Atti del XLIV Convegno Interuniversitario di Bressanone, Bressanone/Brixen 8-10 luglio 2016. Padova: Esedra, 2017, p. 29-40.

37 MARTIN, Richard. Epic as Genre. In: FOLEY, John (éd.). A Companion to Ancient Epic. Malden: Blackwell, 2005, p. 9-19.

38 HARRIS, Joseph. Beowulf in Literary History. In: Pacific Coast Philology, vol. 17 (1982), p. 16-23.

39 ODORICO, Paolo. La cultura della sillogé. 1) II cosiddetto enciclopedismo bizantino. 2) Le tavole dei sapere di Giovanni Damasceno. In : Byzantinische Zeitschrift, vol. 83 (1990), p. 1-23; ODORICO, Paolo. Cadre d'exposition / cadre de pensée - la culture du recueil. In : Orientalia Lovaniensia Analecta, vol. 212 (2011), p. 89-107.
} 
função de refundação, da qual Goyet destaca as aplicações nas esferas da política e da ideologia, também se inscrevem no seio dessa perspectiva central, ainda que sejam transferidos para a cultura narrativa.

Tomando a noção cognitiva de adesão gradual mencionada por P. Moran, entendemos que o Rolandque se limita a enxertar a batalha contra Baligant em um meio narrativo tradicional, ou seja, a morte de Roland em Roncesvale - apresenta um caráter épico menor em comparação com outros textos mencionados acima, porém comparado também com outras canções de gesta. Segundo a minha leitura ${ }^{40}$, o povo de Narbonne retoma um mito familiar arcaico que se relaciona com as primeiras façanhas dos filhos do velho conde Aymeri ${ }^{41}$ e narra a partida de Narbonne, forçado pelo pai ou por Carlos Magno ${ }^{42}$, a partir do grupo de irmãos para a corte do rei onde eles teriam sido condecorados cavaleiros. Esse motivo da expulsão de Narbonne teria permitido tornar os irmãos protagonistas - individualmente ou em grupos - de curtas aventuras paralelas realizadas segundo os patterns (padrões) e motivos próprios da tradição das canções de gesta, espécie de recolha e amostragem do tópico do subgênero da infância. Uma história tradicional torna-se assim uma estrutura para incluir outros episódios baseados, por sua vez, em modelos igualmente tradicionais. A meu ver, é nesse sentido que os Narbonnais poderiam possuir um grau "épico" mais significativo do que o Roland. Claro, devemos também levar em consideração o outro aspecto fundamental da definição de Martin, que é a difusão do texto na cultura: essa é a condição de "popularidade" também enfatizada por Goyet. Nesse aspecto, o Roland parece ter desempenhado um papel mais incisivo na literatura francesa medieval do que os Narbonnais. Pode-se concluir que, no contexto das canções de gesta, faltam textos verdadeiramente épicos, pelo menos segundo a definição do supergênero, embora valha a pena acrescentar que muitos desses textos medievais são também "pontuações" quase isoladas, para as quais a condição marcada em suas respectivas culturas é fraca ou ausente.

\section{Temas antropológicos como ferramentas de comparação}

Nas seções anteriores, observamos como a dialética entre os textos de romance heroico e o conceito mais amplo de epopeia permite o enriquecimento mútuo dos dois pólos: por um lado, o conceito de gênero épico se aprofundou em cada tradição cultural graças à introdução em seu perímetro de definição de modelos antropológicos que permitem considerar a produção local como uma variação de um fenômeno maior e quase universal; por outro lado, a anexação de gêneros de romance heroico ou textos prototípicos dentro do

40 GHIDONI, Andrea. L'eroe imberbe. Le enfances nelle chansons de geste : poetica e semiologia di un genere epico medievale. Alessandria : Edizioni dell'Orso, 2018, p. 82.

${ }^{41}$ Este "mito de família" arcaico não deve ser confundido com aquele identificado no mito indo-europeu de Joël Grisward (Archéologie de l'épopée médiévale. Paris: Payot, 1981). O conto arcaico em questão seria antes um conto heroico plenamente inscrito nas lendas das gestas carolíngias, nas quais viajamos pela origem da família Narbonne, enredo identificável pela comparação dos filhos Narbonnais e Guillaume. A expressão "mito de família" deriva de GUIDOT, Bernard. Le mythe familial de Narbonne dans la Chanson des Aliscans : une insertion souriante. In : Travaux de Littérature, vol. 1 (1994), p. 9-25.

42 As duas variantes constituem a diferença entre os Narbonnais e os Enfances Guillaume: no primeiro caso, a expulsão dos irmãos é provocada pelo pai, que manda os filhos em busca de fortuna em outro lugar; no segundo, é Carlos Magno que usa o pretexto de apresentar os Aymerides à corte, de acordo com as regras do feudalismo [Tradução de comentário feito pelo articulista]. 
domínio épico em uma base antropológica nos permitiu ver como é possível construir novos conceitos épicos e tipos épicos particulares.

Além da definição geral da epopeia e da comparação entre culturas mais ou menos díspares realizada por meio de textos representativos e exemplares, a comparação também pode abranger aspectos mais específicos. Se se pudesse falar de antropologia das culturas ou da literatura nos casos citados, poderíamos falar também de antropologia do texto (literário) nos estudos de que vamos tratar agora, porquanto as comparações entre os textos isolados ou os grupos de textos destacam aspectos específicos. O objetivo desses estudos não é a (re)definição do gênero narrativo épico, e o uso de textos épicos como objetos de comparação transcultural é puramente instrumental. Em casos de comparação anteriores, tentamos focar na especificidade do épico, bem como na especificidade dos diferentes membros desse conjunto, usando uma seleção de um grupo de textos. Nos estudos que agora examinaremos, os textos épicos são utilizados como documentos que testemunham fenômenos antropológicos de âmbito mais amplo. Se estes últimos podem se manifestar em textos épicos, com variações particulares, a escolha de textos heroicos é contingente.

A comparação entre textos épicos de diferentes culturas é, pois, feita com base em construções epistemológicas que muitas vezes não derivam da literatura, mas se desenvolvem em outros campos do conhecimento, como antropologia, sociologia, filosofia, psicologia. O conceito de epopeia é obviamente um conceito ético, produzido por um observador teoricamente distante das culturas e produtos culturais comparados; entretanto, esse conceito tem sido tradicionalmente formulado no campo literário para identificar qualidades comuns a uma série de textos. Escolherei aqui um número limitado desses estudos, que se destacam por sua participação em tendências mais ou menos amplas das humanidades - e que, portanto, não são experiências isoladas.

\section{Emoções}

Uma corrente de estudos literários particularmente desenvolvida na Alemanha adota o conceito de emoção como base de comparação entre textos ${ }^{43}$. De acordo com essa abordagem antropoliterária, as emoções atribuídas a um personagem podem servir de base para reflexões transculturais: são, na verdade, condições universais, que estão presentes em todo ser humano - e a equação, talvez não inteiramente aceitável, prevê que o personagem narrativo seja comparável a um ser humano -, porém que surgem em contextos sociais particulares, para os quais há um cruzamento de elementos universais e variações particulares limitadas às circunstâncias em que o personagem individual expressa os sentimentos sob exame.

43 Sobre esse assunto, ver ALTHOFF, Gerd. Tränen und Freude: Was interessiert Mittelalter-Historiker an Emotionen?. In: Frühmittelalterliche Studien , n. 40 (2006), p. 1-11. 
Um exemplo recente dessa tendência, aplicado a textos épicos da Idade Média românica, é um artigo de Evamaria Freienhofer ${ }^{44}$, que analisa a expressão de raiva na canção francesa antiga Aliscans e sua reescrita em território germânico por Wolfram von Eschenbach, o Willehalm. O estudo proposto pelo artigo encontra-se na encruzilhada de duas tendências seguidas pela pesquisa contemporânea na área das humanidades. Por um lado, a abordagem adota a perspectiva da pesquisa transcultural, que examina objetos e fenômenos históricos e culturais em um processo dinâmico de influências, diferenciações, diálogo entre dois ou mais sistemas culturais; por outro lado, as emoções como motivo literário são consideradas como um objeto de estudo, o que, por seu caráter antropológico universal, permite que os textos literários sejam examinados de uma perspectiva glokale, ou seja, uma abordagem tão atenta à localização do texto quanto às suas relações globais com outros textos de outras culturas: "com a disposição e a função da raiva, escolho um eixo que toca de forma central os interesses atuais da pesquisa transcultural. Surge, assim, no estudo dessa emoção, a construção de si e do estrangeiro, as diferenciações no interior, nas margens e no exterior, bem como a estruturação da comunidade em geral. Ao mesmo tempo, a ênfase na raiva, como veremos, permite uma interpretação global e local - 'glocal' -, que se diferencia sobretudo no plano metodológico" ${ }^{45}$.

O artigo estuda em particular o episódio em que o protagonista Guillaume/Willehalm desencadeia e expressa sua raiva perante a corte do Rei da França. Por meio da semântica da raiva - definida como uma reação à própria depreciação por parte dos outros - e dos sinais com os quais ela é expressa e incorporada no personagem, E. Freienhofer distingue entre textos franceses e alemães. No primeiro caso, a raiva é de fato expressa em uma série de gestos e sintomas físicos; no segundo caso, sua expressão física é omitida, por ser percebida pelo autor como uma violação da etiqueta judicial. Os dois textos respondem, dessa maneira, a dois contextos diferentes que o autor chama de emotional communities (comunidades emocionais). Embora isso não seja explicado nesse estudo - daí o conceito de epopeia parecer ausente - podemos concluir que a ênfase nas emoções, determinada pelo contexto sociocultural em que a canção é recitada, permite observar de uma nova perspectiva a pragmática do texto épico, isto é, como ele se transforma em resposta às necessidades dos participantes nas ocasiões "aurais" em e para as quais o texto épico é divulgado e projetado.

\section{O animal}

O conceito filosófico e antropológico de pós-humano oferece outra perspectiva para trabalhos recentes $^{46}$. Ele repensa o conceito de humano e hibridiza a noção que podemos ter de nossa espécie em

\footnotetext{
${ }^{44}$ FREIENHOFER, Evamaria. Zorn als "glokales" Ereignis. Differenz und Zugehörigkeit in Willehalm und Aliscans, KASTEN, Ingrid; AUTERI, Laura (éd.). Transkulturalität und Translation. Deutsche Literatur des Mittelalters im europäischen Kontext. Berlin: DeGruyter, 2017, p. 111-126.

45 FREIENHOFER, Evamaria, Zorn als “glokales” Ereignis, op. cit., p. 111-112.

46 Ver: MARCHESINI, Roberto. Post-human. Torino: Bollati Boringhieri, 2002; WOLFE, Cary. What is Posthumanism? Minneapolis: University of Minnesota Press, 2010; BRAIDOTTI, Rosi. The Posthuman. Cambridge, Polity Press, 2013.
} 
comparação com máquinas ou animais: ao transferir essa lente cognitiva para o campo literário, podemos então refletir sobre os textos épicos medievais, reconstruindo o modelo heroico que os fundamenta, a fim de trazer à tona aspectos desumanos, não humanos e animais, como fazem, por exemplo, os animal studies (estudos de animais), estudos fortemente influenciados pela filosofia pós-humana ${ }^{47}$. A definição teórica do que se entende por herói nas diversas culturas, assim como os diversos modelos heroicos presentes nos diferentes gêneros narrativos, constituem uma das formas de abordar a definição da epopeia, ainda que a epopeia e o herói nem sempre estejam juntos.

A obra de Antonella Sciancalepore é bastante representativa dessa linha de estudo. Seu livro /l cavaliere e l'Animale $(2018)^{48}$ trata da hipótese de uma persistência de aspectos teriomórficos, vale dizer, da forma animal, na caracterização do cavaleiro na literatura de Oïl (canções de gesta e romances). O teriomorfismo do guerreiro ocorre sempre que o cavaleiro entra fisicamente na morfologia animal, adquire simbolicamente a identidade animal ou é caracterizado por sua interação com um animal. Uma de suas constantes é que o animal é utilizado pelos textos para descrever a qualidade heroica de seu caráter e que a animalidade, física ou simbólica, é o que distingue o herói como ser sobre-humano.

Em um artigo de 2014 mais especificamente dedicado à epopeia da fronteira, A. Sciancalepore ${ }^{49}$ ampliou essa perspectiva para falar do status introdutório do herói. O papel do guerreiro como defensor da comunidade contra tudo o que ele considera como estranho a si mesmo, naturalmente o leva a incorporar o conceito de fronteira. Isso é especialmente verdadeiro para a Idade Média: na realidade, e como era o caso na imaginação medieval, o espaço introdutório não aparece como uma fronteira linear e inequívoca, mas sim como uma fronteira diversificada. O herói medieval atua nesse contexto cronotópico: para poder cumprir o seu papel de protetor da comunidade contra a ameaça externa, ele se situa na periferia territorial e cultural - assim como antropológica - da comunidade e, diante do inimigo, assume algumas de suas características físicas e comportamentais. Essa ambivalência também parece resultar da inevitável contaminação do guerreiro, encarnação da fronteira permeável da comunidade, pelo inimigo a ser combatido, que o leva a se encarregar de parte de sua alteridade e a se situar fora da comunidade humana.

\footnotetext{
47 Ver, por exemplo: COHEN, Esther. Animals in Medieval Perception: The Image of the Ubiquitous Other. In: Manning, Aubrey; Serpell, James (éd.). Animals and Human Society: Changing Perspectives. New York: Routledge, 1994, p. 59-80; Crane, Susan. Animal Encounters: Contacts and Concepts in Medieval Britain. Philadelphia: University of Philadelphia Press, 2013; McCracken, Peggy. Nursing Animals and Cross-Species Intimacy. In: Burns, Jane - Peggy McCracken, Peggy (éd.). From Beasts to Souls: Gender and Embodiment in Medieval Europe. Notre-Dame: University of Notre-Dame Press, 2013, p. 39-64.

${ }^{48}$ SCIANCALEPORE, Antonella. II cavaliere e l'animale. Aspetti del teriomorfismo guerriero nella letteratura francese medievale (XII-XIII secolo). Macerata: Eum, 2018.

49 SCIANCALEPORE, Antonella. II guerriero come confine : lineamenti antropologici del cavaliere belva. In: L'immagine riflessa, vol. 23 (2014), p. 95-120.
} 


\section{Desejo mimético}

Outra via de pesquisa com ferramentas antropológicas é aquela aberta pelas reflexões de R. Girard sobre o desejo mimético e a violência, caminho percorrido por Beate Langenbruch ${ }^{50}$ para o estudo da Coroação de Luís e das canções de gesta em geral: "Se as teses antropológicas de René Girard já têm cerca de cinquenta anos, só recentemente elas foram aplicadas à epopeia medieval; geralmente, as leituras antropológicas da canção de gesta ainda não são muito diversificadas, abrangendo sobretudo o estudo da trifuncionalidade indo-europeia e o do substrato folclórico-mítico"51. Os empréstimos da reflexão antropológica são, pelo contrário, "instrumentos interessantes para lançar uma nova luz tanto sobre o heroísmo épico como sobre a sua ligação com as aspirações de uma sociedade". Para praticar uma antropologia da epopeia, deve-se supor que o herói épico não é apenas um homem excepcional entre os mortais: mais precisamente no mecanismo do desejo mimético, "seu papel no triângulo do desejo também é crucial e explica como os desejos dos outros personagens são construídos em relação a esse pólo central" ${ }^{25}$. Langenbruch também observa que a teoria do desejo mimético de Girard, paradoxalmente, tem sido aplicada muito menos às canções de gesta do que à dinâmica da violência social, embora o desejo, segundo o pensamento girardiano, seja a condição para o desencadeamento da violência ${ }^{53}$. Contudo, embora raramente mobilize exemplos da literatura medieval para seus discursos, Girard usa o último testemunho da literatura cavaleiresca para representar o funcionamento do mecanismo do desejo mimético: Dom Quixote, que segue o ideal cavaleiresco não diretamente, mas pela mediação do modelo do herói Amadis. O desejo mimético implica que o objeto cobiçado pelo sujeito é mediado por um terceiro agente - daí o triângulo - que indica o objeto e excita a vontade do sujeito. Esse mecanismo é identificado por Langenbruch nos vários ramos da Coroação, em que os mediadores que provocam o desejo de usurpadores que tentam se apoderar da coroa da França podem ser Carlos Magno ou Guilherme.

50 LANGENBRUCH, Beate. Héros épiques, désirs mimétiques: une lecture anthropologique du Couronnement de Louis. HECKMANN, Hubert ; LANGENBRUCH, Beate ; LENOIR, Nicolas. "Cel corn ad lunge aleine !". Mélanges en l'honneur de Jean Maurice. Rouen : PURH, 2016, p. 65-84.

51 lbid., p. 67-68. Texto original : “Si les thèses anthropologiques de René Girard ont déjà une cinquantaine d'années, c'est depuis peu seulement qu'on les applique à l'épique médiéval ; globalement les lectures anthropologiques de la chanson de geste sont encore assez peu diversifiées, couvrant surtout l'étude de la trifonctionnalité indo-européenne et celle du substrat folklorico-mythique".

52 lbid., p. 68. Texto original : "son rôle dans le triangle du désir est aussi crucial et explique comment les désirs des autres personnages se construisent par rapport à ce pôle central".

53 A esse respeito, podemos citar a tese Le chant de la violence collective : l'imaginaire persécuteur dans les versions françaises de la Chanson de Roland, defendida por Mathieu Dijoux em Grenoble em 2015. Esse trabalho é notável pela abordagem anti-prototípica de Roland, pela retomada da comparação mitológica na tradição dumeziliana e por sua inspiração girardiana: "A tese de fato se propõe estudar a Canção de Rolando à luz da hipótese de vítima desenvolvida por René Girard, que nos permite pensar sob uma nova luz a estética e a ideologia da canção de gesta. Na verdade, a poética da repetição e a arte da simetria são receptivas à teoria do desejo mimético, assim como a crise épica mantém estreitas analogias com o modelo da crise sacrificial. É em torno da questão antropológica da violência e da ambiguidade da figura do guerreiro mítico que esta obra concilia dois métodos considerados incompatíveis, mas complementares na análise que oferecem da ambivalência dos heróis épicos" [Tradução nossa do resumo em francês apresentado pelo autor do artigo; para ver o resumo original ; consulte: http://www.theses.fr/2015GR(EAL012]. 
O herói se revela assim um pólo essencial do desejo mimético [...]. Mediador poderoso, o herói designa os objetos desejáveis para seus rivais; [...] ele também pode ser um modelo para o leitor-ouvinte. Às vezes, ele se surpreende ao se tornar o sujeito desejante e experimentar desejos despertados por terceiros [...]. Formulando desse modo [...] as ambições de classes e grupos sociais, a canção de gesta é ao mesmo tempo um receptáculo que acolhe e um trampolim que põe em relevo as questões dos desejos miméticos coletivos ${ }^{54}$.

\section{Conclusão}

Esses poucos trabalhos recentes sobre a relação entre textos medievais épicos e heroicos e o uso de ferramentas antropológicas nos estudos literários medievais permitem destacar o diálogo à distância entre estudiosos que refletem sobre esses temas: embora não haja um debate acirrado entre essas ocasionais "pontuações" teóricas, ilhas flutuantes no mar de estudos ecdóticos e especializados - e também por se tratarem de estudos recentes que não são citados entre si e para os quais ainda não é possível registrar um impacto duradouro -, procuramos, todavia, enfatizar as afinidades terminológicas, metodológicas e conceituais, bem como o diálogo e o debate com os estudos de anos anteriores (como foi o caso de Moran com Poirion) e trabalhos semelhantes realizados em outras disciplinas (por exemplo, Langenbruch e Girard). Podemos concluir oferecendo algumas perspectivas e lições que podem ser extraídas dessas reflexões dispersas.

Em primeiro lugar, é necessário um uso mais rigoroso da palavra epopeia em comparação com os textos medievais: Moran mostra, por exemplo, que o uso desse conceito implica uma abordagem antropológica e comparativa, muito distinta de uma abordagem histórica ou semiológica.

O gênero das canções de gestas deve ser avaliado em termos diacrônicos porque suas "regras" mudam com o tempo. De modo que não deve ser descrito com base em um único protótipo, como costumava acontecer no passado com o Roland: a história e a antropologia podem talvez se juntar na tentativa de definir as origens do gênero, para mostrar como um corpo de textos fortemente caracterizados culturalmente podem ser precedidos por "formas simples" 55 , tipos universais, que - com uma comparação cuidadosa - podem nos revelar os ancestrais diretos das canções de gesta - pelo menos de forma genérica, já que sua substância real é inacessível.

Quanto à definição de epopeia, parece-me que agora tende cada vez mais a uma conceituação dinâmica, em que a epopeia não é uma substância fixa e universal, antes se torna um recipiente que cada cultura "épica" pode preencher de conteúdos específicos e multifacetados, devolvendo uma imagem polifônica de certos textos

\footnotetext{
${ }^{54}$ LANGENBRUCH, Beate. Héros épiques, désirs mimétiques, op. cit., p. 84. Texto original: "Le héros se révèle ainsi un pôle essentiel dans le désir mimétique [...]. Puissant médiateur, le héros désigne les objets désirables à ses rivaux ; [...] il peut aussi être un modèle pour le lecteur-auditeur. Parfois on le surprend à devenir le sujet désirant, et à éprouver des désirs suscités par des tiers [...] Formulant ainsi [...] les ambitions de classes et de groupes sociaux, la chanson de geste est en même temps un réceptacle qui accueille et un tremplin qui fait rebondir puissamment les enjeux des désirs mimétiques collectifs".

55 A referência é naturalmente a JOLLES, André. Einfache Formen. Halle, 1930.
} 
épicos ou das sociedades que os compõem ou, melhor ainda, como uma "máquina" realizando funções específicas e um "trabalho" dentro uma cultura.

Finalmente, embora reconhecendo a importância e eficácia heurística dos conceitos emprestados da antropologia - emoções, animalidade, desejo mimético ...-, no entanto, deve-se ter cuidado com os mecanismos automáticos. Tanto nos textos medievais como na literatura de outros horizontes culturais, os personagens certamente possuem características humanas que nos permitem nos identificarmos com eles, pois o homem não é capaz de imaginar um "agente" desprovido de características humanas; e se às vezes nos parecem desumanos, animais, a antropologia contemporânea nos ensina que esses traços também são inerentes à nossa natureza. Entretanto, resta demonstrar que o ser humano pode estar completamente sobreposto ao herói, considerado não apenas como um homem que realiza empreendimentos extraordinários, mas também como um indivíduo de uma categoria distinta, a meio caminho entre o humano e o divino, monstruoso, animal, santo ${ }^{56}$. O herói apresenta aspectos humanos que, sem dúvida, podem ser interpretados de forma antropológica, sem contudo esquecer que essa leitura é parcial e que ele é uma entidade "construída" na globalidade da cultura humana, através de textos, lendas, representações plásticas, cultos religiosos. Se fôssemos indicar um possível caminho que os estudos épicos podem percorrer com sucesso, certamente seria o do estudo do herói, não em termos humanos ou como um documento de nossa identidade psíquica ou emocional, mas como um conceito culturológico, como um personagem cujo estudo é capaz de reunir disciplinas das ciências humanas muitas vezes separadas: literatura, antropologia, história das religiões.

\section{Referências bibliográficas}

ALTHOFF, Gerd. Tränen und Freude : Was interessiert Mittelalter-Historiker an Emotionen ?. In: Frühmittelalterliche Studien, n. 40 (2006), p. 1-11.

AVALLE, d'Arco Silvio. Cultura e lingua francese delle origini nella Passion di Clermont-Ferrand. Milano-Napoli: Ricciardi, 1962.

BRAIDOTTI, Rosi. The Posthuman. Cambridge: Polity Press, 2013.

CRANE, Susan. Animal Encounters : Contacts and Concepts in Medieval Britain. Philadelphia: University of Philadelphia Press, 2013.

COHEN, Esther. Animals in Medieval Perception : The Image of the Ubiquitous Other. In: MANNING, Aubrey; SERPELL, James (éd.). Animals and Human Society : Changing Perspectives. New York: Routledge, 1994, p. 5980.

DIJOUX, Mathieu. Le chant de la violence collective : I'imaginaire persécuteur dans les versions françaises de la Chanson de Roland. Thèse Université Grenoble-Alpes, 2015, URL : http://www.theses.fr/2015GREAL012.

FOWLER, Alastair. Kind of Literature. An Introduction to the Theory of Genres and Modes. Oxford: Oxford University Press, 1982.

\footnotetext{
${ }^{56}$ Para se ter uma ideia da construção do herói em uma cultura, pode-se ler BRELICH, Angelo. Gli eroi greci. Un problema storico-religioso. Adelphi: Milano, 2010 [1e éd. Edizioni dell'Ateneo, Roma, 1958].
} 
FREIENHOFER, Evamaria. Zorn als "glokales" Ereignis. Differenz und Zugehörigkeit in Willehalm und Aliscans. In: KASTEN, Ingrid; AUTERI, Laura (éd.). Transkulturalität und Translation. Deutsche Literatur des Mittelalters im europäischen Kontext. Berlin: DeGruyter, 2017, p. 111-126.

GHIDONI, Andrea. Per una poetica storica delle chansons de geste. Elementi e modelli. Venezia : Edizioni Ca' Foscari, 2015 (en ligne : http://edizionicafoscari.unive.it/it/edizioni/libri/978-88-97735-91-5/);

GHIDONI, Andrea. The Origins of the Narrative Structures in the Chansons de Geste. In: Perspectives médiévales, n. 35 (2014), URL : http://peme.revues.org/4321

GHIDONI, Andrea. Sviluppo diacronico e diatopico delle chansons de geste. In : DIVIZIA, Paolo (éd.). Il viaggio del testo. Atti del Convegno internazionale di Filologia italiana e romanza (Brno, 19-21 giugno 2014). Alessandria : Edizioni dell'Orso, 2017, p. 395- 406

GHIDONI, Andrea. Modello ossidionale e modello agiografico:patterns a confronto nella preistoria delle chansons de geste. In : CARERI, Maria (éd.) Par deviers Rome m'en revenrai errant" XXe Congrès International de la Societé Rencesvals pour l'étude des épopées romanes. Roma : Viella, 2017, p. 515-525.

GHIDONI, Andrea. Cultura e poetica dei dittici epici medievali. In: PIOLETTI, Antonio; RAPISARDA, Stefano (éd.). Forme letterarie del Medioevo romanzo : testo, interpretazione e storia XI Congresso Società Italiana di Filologia Romanza (Catania, 22-26 settembre 2015). Soveria Mannelli: Rubbattino, 2016, p. 237-253.

GHIDONI, Andrea. Forme epiche arturiane : polifonia medievale e preistoria del romanzo nel Culhwch ac Olwen. In: BARBIERI, Alvaro ; GREGORI, Elisa (éd.). Commixtio. Forme e generi misti in letteratura. Atti del XLIV Convegno Interuniversitario di Bressanone, Bressanone/Brixen 8-10 luglio 2016. Padova: Esedra, 2017, p. 2940.

GHIDONI, Andrea. Narrazioni eroopoietiche mediolatine : "punteggiature" nell'evoluzione delle letterature profano-volgari. In: Mittellateinisches Jahrbuch, vol. 53, n. 3 (2018), p. 399-422.

GHIDONI, Andrea. L'eroe imberbe. Le enfances nelle chansons de geste : poetica e semiologia di un genere epico medievale. Alessandria : Edizioni dell'Orso, 2018.

GOYET, Florence. Penser sans concepts : fonction de l'épopée guerrière. Iliade, Chanson de Roland, Hôgen et Heiji monogatari. Paris : Honoré Champion, 2006.

GOYET, Florence. L'épopée refondatrice : extension et déplacement du concept d'épopée. In : Le Recueil Ouvert [En ligne], mis à jour le : 31/05/2018, URL: http://ouvroir-litt-arts.univ-grenoblealpes.fr/revues/projetepopee/165-le-travail-epique-definition-de-l-epopee-refondatrice.

GRISWARD, Joël. Archéologie de l'épopée médiévale. Paris : Payot, 1981.

GUIDOT, Bernard. Le mythe familial de Narbonne dans la Chanson des Aliscans: une insertion souriante. In : Travaux de Littérature, vol. 1 (1994), p. 9-25.

HARRIS, Joseph. Beowulf in Literary History. In: Pacific Coast Philology, vol. 17 (1982), p. 16-23.

HOEPFFNER, Ernest. Les rapports littéraires entre les premières chansons de geste. In : Studi Medievali, n. 4 (1931), pp. 233-258 ; n. 6, p. 45-81.

KÜPPER, Joachim. Transzendenter Horizont und epische Wirkung. Zu Ilias, Odyssee, Aeneis, Chanson de Roland, El Cantar de mío Cid und Nibelungenlied. In: Poetica, vol. 40 (2008), p. 211-267.

LAKOFF, George. Women, Fires and Dangerous Things: What Categories Reveal about the Mind. Chicago: University Press, 1987. 
LANGENBRUCH, Beate. Héros épiques, désirs mimétiques : une lecture anthropologique du Couronnement de Louis. In: HECKMANN, Hubert; LANGENBRUCH, Beate; LENOIR, Nicolas. "Cel corn ad lunge aleine !". Mélanges en I'honneur de Jean Maurice. Rouen : PURH, 2016, p. 65-84.

MARCHESINI, Roberto. Post-human. Torino: Bollati Boringhieri, 2002.

MARTIN, Richard. Epic as Genre. In: FOLEY, John (éd.). A Companion to Ancient Epic. Malden: Blackwell, 2005, p. 9-19.

MCCRACKEN, Peggy. Nursing Animals and Cross-Species Intimacy. In: BURNS, Jane; PEGGY MCCRACKEN, Peggy (éd.). From Beasts to Souls : Gender and Embodiment in Medieval Europe. Notre-Dame: University of NotreDame Press, 2013, p. 39-64.

MORAN, Patrick. Genres médiévaux et genres médiévistes : l'exemple des termes chanson de geste et épopée. In : Romania, vol. 136 (2018), p. 38-60.

NEEDHAM, Rodney. Polythetic Classification: Convergence and Consequences. In: Man, n. 10 (1975), p. 349-369. ODORICO, Paolo. La cultura della sillogé. 1) II cosiddetto enciclopedismo bizantino. 2) Le tavole dei sapere di Giovanni Damasceno. In: Byzantinische Zeitschrift, vol. 83 (1990), p. 1-23.

ODORICO, Paolo. Cadre d'exposition / cadre de pensée - la culture du recueil. In : Orientalia Lovaniensia Analecta, vol. 212 (2011), p. 89-107.

POIRION, Daniel. Chanson de geste ou épopée ? Remarques sur la définition d'un genre. In : Travaux de linguistique et de littérature, n. 10 (1972), p. 7-20.

ROSCH, Eleanor. Natural Categories. In : Cognitive Psychology, n. 4 (1973), p. 328-350

SCHAEFFER, Jean-Marie. Qu'est-ce qu'un genre littéraire? Paris: Seuil, 1989.

SCHNUR-WELLPOTT, Margrit. Aporien der Gattungstheorie aus semiotischer Sicht. Tübingen : Narr, 1983.

SCIANCALEPORE, Antonella. II guerriero come confine : lineamenti antropologici del cavaliere belva. In: L'immagine riflessa, vol. 23 (2014), p. 95-120.

SCIANCALEPORE, Antonella. II cavaliere e l'animale. Aspetti del teriomorfismo guerriero nella letteratura francese medievale (XII-XIII secolo). Macerata : Eum, 2018.

VINCLAIR, Pierre. Le roman fait l'épopée. In : Le Recueil Ouvert [En ligne], mis à jour le: 26/03/2018 URL: http://ouvroir-litt-arts.univ-grenoble-alpes.fr/revues/projet-epopee/166-le-roman-fait-l-epopee.

WATHELET-WILLEM, Jeanne (1964). À propos de la technique formulaire dans les plus anciennes chansons de geste. In : RENSON, Jean (éd.). Mélanges de linguistique romane et de philologie médiévales offerts à $\mathbf{M}$. Maurice Delbouille. Gembloux : Duculot, 1964, vol. II, p. 705-27.

WOLFE, Cary. What is Posthumanism? Minneapolis: University of Minnesota Press, 2010.

ZUMTHOR, Paul. Essai de poétique médiévale. Paris: Le Seuil, 2000 [1972]. 